\title{
A busca por financiamento da inovação na indústria da construção civil - Rio de Janeiro
}

Sílvia Valeriano Gomes

silviavaleriano@id.uff.br

Universidade Federal Fluminense (UFF)

Niterói, Rio de Janeiro, Brasil

João Alberto Neves dos Santos

joaoneves@id.uff.br

Universidade Federal Fluminense (UFF), Niterói, Rio de Janeiro, Brasil

\section{Branca Regina Cantisano dos} Santos

brancaterra@gmail.com
Universidade do Estado do Rio de Janeiro (UERJ), Rio de Janeiro, Rio de Janeiro, Brasil

\section{Silva Riscado Terra}

brancaterra@gmail.com

Universidade do Estado do Rio de Janeiro (UERJ), Rio de Janeiro, Rio de Janeiro, Brasil

\author{
RESUMO
}

A necessidade de se inovar está cada vez mais evidenciada como sendo caminho, pelo qual os países têm a oportunidade de agregar valor as suas respectivas economias. Além de ser necessário à resolução de questões como, o alto volume de resíduos sólidos na construção civil. Para isso existe a necessidade de fomento governamental como forma de indução do processo de inovação. Objetivou-se identificar as dificuldades de acesso ao financiamento junto à agência de fomento governamental, no caso, a Fundação Carlos Chagas Filho de Amparo à Pesquisa do Estado do Rio de janeiro - FAPERJ. Através do mapeamento dos editais lançados de 2010 a 2014 e seus respectivos projetos contemplados, foi possível obter a classificação dos projetos por área de conhecimento, o que tornou possível averiguar que a Engenharia Civil obteve financiamento junto à Agência de apenas $1,12 \%$ do total projetos aprovados. Foi aplicado um survey conseguindo mapear 12 Fatores críticos, que dificultam o acesso ao financiamento no processo. A confiabilidade encontrada foi de 0,867 , na validação do conteúdo encontrouse uma perda de $6,10 \%$ onde consta os 12 Fatores críticos validos. Na validação do constructo, tem-se o Teste de KMO com 0,837 e o teste de esfericidade dei Bartlett's 0,000 . Através da análise dos carregamentos dos fatores críticos comprovou a existência de um único constructo, sendo este composto por três subconstructos (Problemas inerentes à Agência de fomento; Problemas relacionados aos profissionais; e Problemas referentes aos Editais - Agência e Legislação).
\end{abstract}

PALAVRAS-CHAVE: Inovação Construção civil. Agência de fomento. Linhas de financiamento. 


\section{INTRODUÇÃO}

No atual contexto empresarial, a inovação se tornou um ponto crucial na transformação da maneira como interagem as organizações e a sociedade, com o objetivo de prospecção dos segmentos de negócio para que as empresas prosperem em longo prazo.

Para tornar-se relevante no cenário global, é importante que o Brasil aumente sua capacidade de inovar, pois isso pode ser o ponto crucial para que o país passe a fazer parte de um seleto grupo de nações que tenha na inovação a base para seu crescimento. Na pesquisa da escola mundial de formação de executivos - INSEAD e da Organização Mundial de Propriedade Intelectual - OMPI (EXAME, 2015) mostra que o país está em 70ㅇ lugar em inovação, caindo nove posições desde o último ranking em 2014.

Se por um lado, o resultado da pesquisa realizada pela INSEAD e OMPI mostra não apenas as consequências da continuada baixa disponibilidade de recursos para $C, T \& 1$, mas também a fragilidade das estratégias realizadas até o momento, por outro lado pode ter como consequência o redirecionamento das ações do Governo, em relação a forma como irá promover a inovação no país, o que vai ao encontro das metas do Plano Brasil Maior de 2010-2014, dentro de sua Dimensão Sistêmica, pois é importante "consolidar o Sistema Nacional de Inovação - SNI, por meio da ampliação das competências científicas e tecnológicas e sua inserção nas empresas", visando aproveitar um ponto forte do SNI: a existência de um núcleo de empresas inovadoras no Brasil com capacidade de liderar o processo de modernização produtiva (BRASIL, 2014).

Buscando refletir o vigor do setor de Construção Civil que, em 2013, era composto por cerca de 111,9 mil empresas que realizaram incorporações, obras e serviços da construção no valor de $\mathrm{R} \$ 357,7$ bilhões, assinalando um aumento real de 5,8\% em relação ao ano de 2012 e de 27,6\% no confronto com 2010 (IBGE, 2013) e que empregaram cerca de 2,9 milhões de pessoas em 2013, número superior aos 2,8 milhões de pessoas ocupadas em 2012 e ao 2,5 milhão de ocupados em 2010.

É certo que existem diversas agências de fomento que financiam as iniciativas e projetos de inovação no estado do Rio de Janeiro. Por isso, preliminarmente, foi realizado um mapeamento com base nos editais de fomento da Fundação de Amparo à Pesquisa do Estado do Rio de Janeiro FAPERJ e em seus respectivos resultados, de forma a identificar os setores do mercado que mais têm alcançado sucesso na obtenção de financiamento não reembolsável, de projetos de inovação, com o intuito de analisar como é a participação da indústria da construção civil nesse processo.

Recentemente, com a transformação do Marco Regulatório de Ciência, Tecnologia e Inovação na Lei no 13. 243 de 11 de janeiro de 2016, foi apresentada uma regulamentação menos burocrática aos trâmites de incentivo à inovação no País.

O objetivo deste artigo é identificar as dificuldades de acesso ao financiamento junto à agência de fomento governamental, no caso, a Fundação Carlos Chagas Filho de Amparo à Pesquisa do Estado do Rio de Janeiro - FAPERJ. Além de verificar em que patamar se encontra a Engenharia Civil (Construção Civil) nesta questão. 
O nível de desenvolvimento de um país é geralmente mensurado por meio de uma combinação de características (transporte, habitação, educação, saúde, comunicação e geração de consumo de energia). Com esses elementos desenvolve-se a construção de ativos que tem a necessidade de elevados períodos de maturação, custos iniciais e longevidade, sendo responsáveis por significativos impactos social, ambiental e econômico (PAULA, 2016). Os gastos com moradia representaram $12 \%$ da renda familiar entre 2002 e 2009 (IPEA, 2010), em 2011 o déficit habitacional representou em torno de $9,0 \%$ do total de domicílios estimados em todo país, ou seja, foi identificada a necessidade de 5,4 milhões de novos domicílios (FURTADO, NETO e KRAUSE, 2013).

Os investimentos no ativo imobilizado realizados em 2011 pelas empresas da construção civil somavam cerca de $\mathrm{R} \$ 8,5$ bilhões, enquanto no ano anterior totalizavam cerca de $\mathrm{R} \$ \mathbf{7 , 4}$ bilhões. Ocorreu um crescimento de investimento de $14,8 \%$ com relação a 2010. O investimento em máquinas e equipamentos foi o principal destaque, representando $42,9 \%$ do total investido, seguido por meios de transporte com $26,0 \%$, terrenos e edificações com $19,6 \%$ e outras aquisições (móveis, microcomputadores, etc) com 11,5\% em 2011 (IBGE, 2014).

A Câmara Brasileira da Indústria da Construção (CBIC), no Projeto Inovação Tecnológica, usou a definição de inovação do Manual de Oslo, caracterizando as inovações em construção civil da seguinte forma:

- Inovações de produto: inovações no produto edifício ou em um ou mais de seus subsistemas, componentes ou materiais;

- Inovações de processo: inovações no processo de produção dos edifícios, que podem ser obtidas por meio de inovações em produtos intermediários, como tipos de subsistemas, componentes ou materiais que têm impacto no processo;

- Inovações organizacionais: inovações que afetam a organização das empresas do setor e seus processos não diretamente relacionados à produção, como implementação de softwares, criação de novos métodos para processos como planejamento, orçamento, projeto, etc; e

- Inovações de marketing: inovações que se referem a novas formas de relacionamento com os clientes, promoção dos produtos, comunicação com o mercado (MONTEIRO FILHA, 2010, p.377).

Devido a esses conceitos, podem surgir as seguintes inovações na construção civil:

- Inovações que agregam características de desempenho aos edifícios; Inovações que afetam o processo produtivo;

- Inovações que afetam os processos internos das empresas ligados não só ao produto, mas processos administrativos, de atendimento ao cliente, etc; e

- Inovações que afetam a promoção do produto e sua colocação no mercado (MONTEIRO FILHA, 2010, p. 378).

$\mathrm{Na}$ cadeia produtiva das edificações, existe uma necessidade de se elevar a produtividade, principalmente quando se leva em conta a necessidade de acelerar investimentos em construção civil, além de ser por causa do elevado déficit habitacional no país, mas também por causa da grande deficiência em 
infraestrutura que deve ser superada. Ainda mais devido os compromissos assumidos pelo Brasil para a realização da Copa do Mundo e da Olimpíada nesta década (MONTEIRO FILHA, 2010).

Em 2008 nos EUA o governo investiu em pesquisa e desenvolvimento 89 bilhões sendo que US\$ 26 bilhões foram para empresas, principalmente por encomendas onde o governo promete comprar os produtos e o desenvolvimento tecnológico, correspondendo a $15 \%$ do gasto total realizado pelas empresas norte-americanas em P\&D. O Reino Unido, o Estado investe 1,5 bilhão de dólares por ano nas empresas sendo esse valor igual a $9 \%$ do total empregado pela iniciativa privada em P\&D esse valor igual a $9 \%$ do total empregado pela iniciativa privada em Pesquisa e Desenvolvimento (P\&D). Já a França e a Alemanha investem consecutivamente US\$1,6 bilhão e US\$2 bilhões anuais, correspondendo a $11 \%$ e a $9 \%$ do gasto anual das empresas. Os incentivos financeiros dos países que compõem a Organização para a Cooperação e Desenvolvimento Econômico (ODCE) correspondem a 10\% dos recursos usados pelas empresas em P\&D. Sendo esse tipo de subsídio tão importante que um acordo da Organização Mundial do Comércio (OMC), subscrito pelo Brasil permite aos governos subsidiarem em até $75 \%$ do valor do custo total de um projeto atividades empresariais em P\&D (Senado Federal, 2012).

Os tipos de financiamento mais usados pelos países são: 0 financiamento não reembolsável para pesquisa acadêmica; $O$ financiamento não reembolsável para pesquisa privada pré-competitiva; A subvenção; $O$ financiamento reembolsável em condições favorecidas; A participação do Estado no capital do empreendimento; e $\mathrm{O}$ empréstimo de capital empreendedor para desenvolvimento de pequenas empresas de base tecnológica.

A necessidade de tornar mais forte a indústria nacional na implementação de inovações tecnológicas com capacidade de favorecer sua competitividade induziu o governo brasileiro a criar mecanismos que promovesse a inovação, incluindo o financiamento e o incentivo a execução de atividades e Pesquisa, Desenvolvimento e Inovação (P\&D\&I), principalmente através de projetos de pesquisa e desenvolvimento em cooperação com as Instituições Científicas e Tecnológicas (ICT), segundo Bueno e Torkonian (2014).

Com o objetivo de fomentar a inovação tecnológica nas empresas nos últimos anos, tem-se as seguintes ações do Governo brasileiro:

- A Lei de Inovação (Lei no 10.973 de 02.12.2004) e o Decreto no 5.563 de 11.10.2005) que apresenta mecanismos de apoio e estímulo à constituição de ambientes especializados e cooperativos de inovação;

- O Marco Regulatório de Ciência, Tecnologia e Inovação na Lei no 13. 243 de 11.01.2016 apresenta uma regulamentação menos burocrática aos tramites de incentivo a Inovação ao País;

- A Lei do Bem (Lei no 11.196 de 21.11.2005 e Decreto no 5.798 de 07.06.2006) que dispõe sobre incentivos à inovação tecnológica e incentivos fiscais por si ou em convênio com ICT.

Dentre as Políticas e Planos para o desenvolvimento da ciência, tecnologia, inovação e competitividade da indústria nacional tem-se: 
- Política Industrial, Tecnológica e de Comércio Exterior - PITCE 2003-2007, cujo objetivo é realizar a transformação da base produtiva para elevar a mesma a um patamar de maior valor agregado;

- Plano de Ação Ciência, Tecnológia e Inovação (PACTI 2007-2010) criado com o intuito de priorizar a ampliação da inovação nas empresas e a consolidação do sistema nacional de ciência, tecnologia e inovação;

- A Política de Desenvolvimento Produtivo (PDP 2008-2010), que tem como objetivo fortalecer a estrutura industrial para atuar com competitividade e cada vez mais focado em inovação, além de diferenciação;

- O mais recente é o Plano Brasil Maior (2011-2014), focado em estimular a competitividade e o crescimento do País levando em consideração as experiências acumuladas e avanços obtidos anteriormente;

- Estratégia Nacional de Ciência, Tecnológia e Inovação (ENCTI), a qual o objetivo base desse plano são os estímulos a inovação.

No país os mecanismos de apoio financeiro podem ser classificados em três categorias mais presentes, segundo Bueno e Torkonian (2014): Financiamentos não reembolsáveis; Financiamento reembolsável; e Incentivos Fiscais.

Segundo FIRJAN (2015), a estruturação das principais agências e instituições de fomento que atendem ao estado do Rio de Janeiro, que é a região foco dos estudos deste artigo, compõem-se conforme a Figura1: 
Figura 1: Principais agência e instituições de fomento à inovação

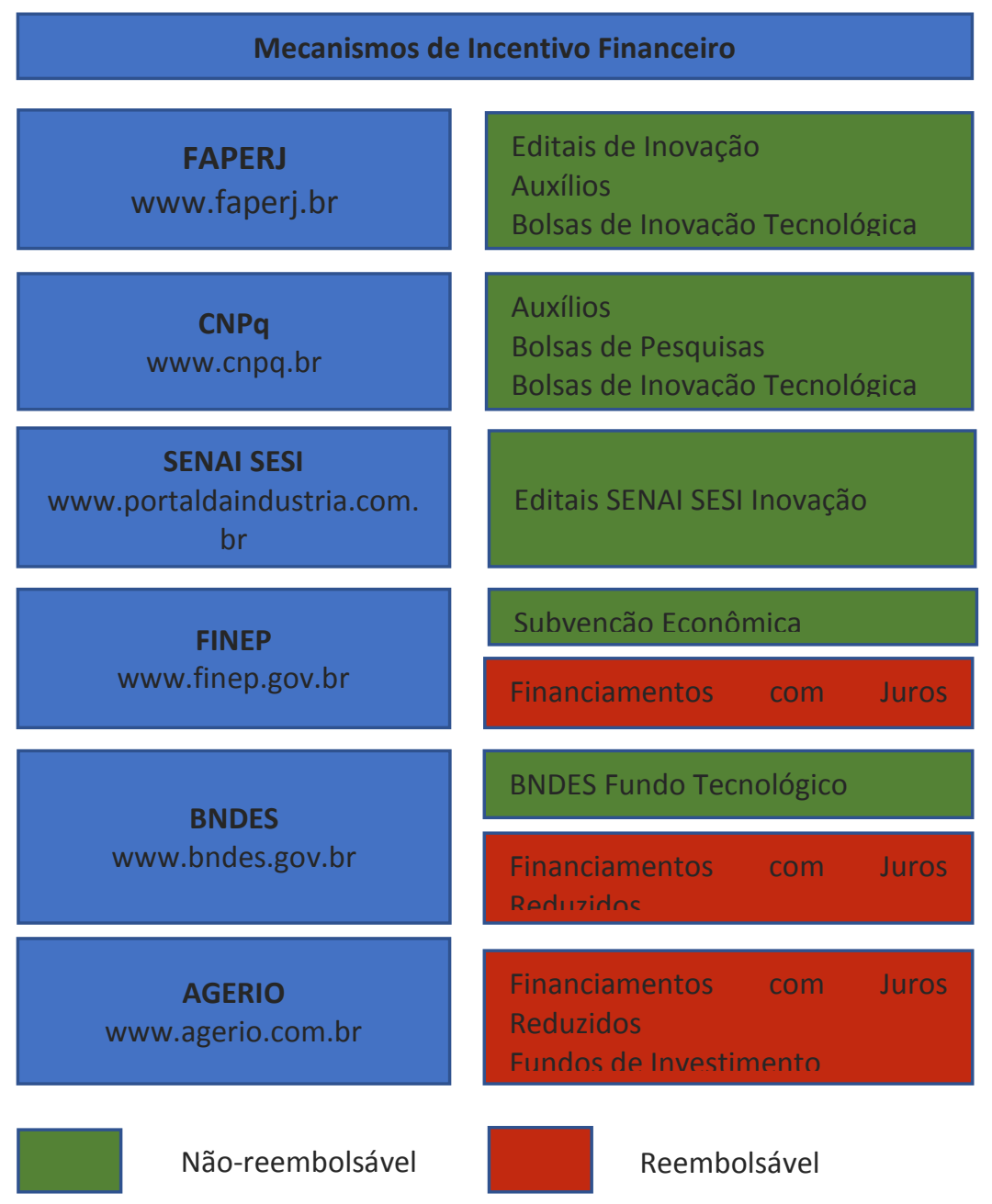

Fonte: FIRJAN,2015

O órgão de fomento escolhido como base de análise para este estudo foi a Fundação Carlos Chagas Filho de Amparo à Pesquisa do Estado do Rio de Janeiro (FAPERJ) atualmente é uma das principais agências de fomento à pesquisa no cenário nacional. A sua missão é estimular e financiar atividades científicas e tecnológicas de pesquisadores e empreendedores vinculados a instituições científicas e tecnológicas e a empresas, sejam elas públicas ou privadas do estado do Rio de Janeiro e do País. No período dos últimos 8 anos, ocorreu um incremento do orçamento, propiciando a execução financeira em cerca de $R \$ 2,5$ bilhões, em resposta ao lançamento de mais de 250 editais específicos à Inovação, apoiando projetos apresentados por pesquisadores e empreendedores oriundos de todos os 92 municípios fluminenses (FAPERJ, 2014).

No setor da construção civil por exemplo um dos problemas que necessita de implementação de inovações para mitigar a questão dos resíduos sólidos. No Brasil são coletados $90,6 \%$ do volume total de resíduos sólidos gerados, sendo a construção civil responsável por gerar $57,7 \%$ dos resíduos sólidos coletados (ABRELPE, 2014). No intuito de melhor gerenciamento do processo de produção e minimizar o desperdício de materiais, as empresas de construção civil aderiram à medição de desempenho através de indicadores de acordo com Duarte (2011). 
Neste cenário foi ressaltada a importância de monitorar indicadores de desempenho dentro do canteiro de obras, sendo considerada uma ferramenta de monitoramento de processos produtivos, ou seja, uma ferramenta de melhoria contínua. Com a avaliação comparativa entre os indicadores das construtoras é possível identificar as melhores práticas associadas às tecnologias de construção baseadas em cimento de empresas de construção (Lordsleem, Andrade and Pinho, 2011).

Um exemplo desta aplicação temos os resultados obtidos na pesquisa descrita em um programa realizado com a participação de doze construtoras localizadas na cidade de Recife, no Brasil, participantes do processo de benchmarking da pesquisa "Implementação de um sistema de indicadores de desempenho de tecnologias de construção baseadas em cimento da Comunidade de Construção da cidade de Recife no Brasil - PROGRIDE", segundo Lordsleem Jr.and Lima (2014).

A FAPERJ contemplou alguns projetos voltados para mitigação do volume de resíduos sólidos urbanos dentro do período da pesquisa 2010 - 2014, em consequência da importância desta questão se busca financiamento para desenvolver pesquisas nesta área.

\section{MÉTODOS}

Inicialmente, foi realizado um mapeamento de todos os projetos contemplados no período de 2010 a 2014 pela FAPERJ, desta forma foi possível identificar as áreas de maior atuação na submissão de projetos que obtiveram financiamento da FAPERJ. Por isso, foi feita uma pesquisa descritiva, com a finalidade de expor características de uma população específica, neste caso dos profissionais, que tiveram projetos contemplados, atuantes na área empresarial e acadêmica do Estado do Rio de Janeiro.

Em um segundo momento, foi realizada uma pesquisa exploratória e qualitativa, com vistas a obter informações através da aplicação de um questionário preliminar com questões abertas, buscando informações sobre o que dificultava a obtenção do financiamento oferecido pela FAPERJ. Posteriormente, foi realizada uma pesquisa exploratória e quantitativa, por meio de um questionário com questões fechadas, abordando os principais itens levantados na pesquisa preliminar. Essa última fase, uma pesquisa explicativa, teve como objetivo elencar quais eram os principais fatores críticos, conforme opinião dos profissionais atuantes.

Por outro lado, quanto aos meios, foi feita uma investigação bibliográfica, pois foi realizado um apanhado de informações em periódicos, revistas internacionais da área de business, relatórios dos programas desenvolvidos pelo governo do Brasil e entre outras fontes de informação. A pesquisa também foi documental, pois foi realizada uma análise dos documentos internos, os editais, da FAPERJ. Por fim, foi uma pesquisa de campo, pois existiu uma investigação empírica, realizada através da aplicação dos questionários. 
Segundo Vergara (2000), população deve ser entendida como um conjunto de elementos que possuem características que serão objeto de estudo. Para fins acadêmicos a população da pesquisa em questão são profissionais atuante no meio empresarial (Engenheiros e outros profissionais) do Estado do RJ e pesquisadores atuantes na área acadêmica sendo direcionados à inovação.

No primeiro questionário, ocorreu a coleta da opinião dos profissionais atuantes no mercado com relação aos fatores que estão dificultando o acesso ao financiamento à inovação. Este questionário foi realizado de forma aberta para os entrevistados expusessem suas opiniões a respeito. Elencaram cada entrevistado cinco fatores que impactam na dificuldade de se obter financiamento à inovação. Os fatores identificados na coleta de dados através do questionário preliminar foram utilizados no questionário definitivo de forma fechada. Dessa forma, no questionário fechado foram formuladas questões que tinham por base os estudos realizados anteriormente a respeito do assunto em questão e as respostas ao questionário preliminar. Este tipo de questionário foi bastante objetivo, o que facilitou o tratamento e análise da informação.

Um dos aspectos fundamentais na criação de um questionário fechado é a escolha da escala a ser usada para o formato de resposta. O método usado foi a escala de Likert, a qual é classificada como intervalar. A escala de Likert é utilizada para obter o grau de concordância que o respondente possui com uma determinada afirmação (HAYES,1997).

\section{Análise estatística de dados}

A análise descritiva detalhada permite ao pesquisador conhecer os dados, organizá-los e sintetizá-los de forma a obter o máximo de informações possíveis a respeito do objeto pesquisado. Vários pesquisadores salientam a importância da validação dos instrumentos de medição, sem a qual as pesquisas não têm valor. Conforme Rolim (1999), nenhuma discussão de metodologia quantitativa é completa sem associação do conceito de validade e confiabilidade.

Em um senso geral, "um instrumento é válido se ele mede o que se propõe" (NUNNALLY, 1967, p. 75). Outra definição bastante relevante foi sugerida por Hayes (1997) referindo-se ao grau no qual as evidências suportam as inferências realizadas. Na validação podem ser utilizadas dois tipos: validação de conteúdo e validação de constructo.

No aspecto de validade de Conteúdo, uma das formas é verificar o número de dados perdidos, ou seja, perguntas não respondidas ou respostas NE (não entendi). Se esse a percentagem de perdas for maior que $10 \%$ considera-se que há problema no conteúdo (BYRD e TURNER, 2001).

Para verificar a validade do constructo, normalmente é utilizada a análise fatorial (HAIR et Al., 2005). Os testes de Kaiser-Meyer-Olkin (KMO) e de Esfericidade de Bartlett tem como objetivo verificar se a aplicação da análise fatorial tem validade para as variáveis escolhida. $\mathrm{O} \mathrm{KMO}$ varia de 0 à 1 . Um valor de 0 indica que a soma de correlação parcial é grande em relação à soma das correlações, indicando a difusão do padrão de correlação. Já os valores próximos de 1 indica que os padrões de correlação são relativamente compactos e com 
isso a análise fatorial deve gerar fatores distintos e confiáveis. Desta forma, é recomendável aceitar valores maiores que 0,5. Já o teste de esfericidade de Bartlett é usado para examinar a hipótese de que as variáveis não sejam correlacionadas na população, se P-valor é menor que 0,05 , rejeita-se a hipótese (FIELD, 2005). Os resultados obtidos para as duas medidas (Teste de esfericidade de Bartlett e Medida de adequacidade da amostra) indicam que a análise fatorial é adequada.

Além disso, para a análise fatorial, existem critérios de extração das cargas de cada variável existente. No trabalho, o critério predominante será o "A priori", o qual é utilizado quando o pesquisador já possui previamente definido o número de fatores que devem ser extraídos. Essa abordagem é muito útil se o analista está testando uma teoria ou hipótese sobre o número de fatores a serem extraídos. Este critério está normalmente associado a uma abordagem confirmatória (HAIR et al., 2005).

Na etapa da análise de confiabilidade, a mesma está relacionada com o grau de verdade associado aos níveis de percepção medidos pelo questionário. A Estimativa do Alfa de Cronbach, a qual foi utilizada nesta pesquisa, indica se o inter-relacionamento entre os itens do questionário é alto, porém sem necessitar de correções. Este pode variar de 0 a 1 , onde 0 significa total ausência de consistência entre os itens, enquanto 1 demonstra presença de consistência interna de $100 \%$. A grande maioria dos especialistas utiliza como limite de aceitação do Alfa de Cronbach o valor de 0,70 (NUNNALY, 1967; HAYES, 1997), porém Nunnaly afirma ser aceitável o estabelecimento de um limite menor, de 0,60 , quando se utiliza instrumentos novos.

Sendo assim, a estimativa do Alfa de Cronbach indica o quanto os itens do questionário estão inter-relacionados e, diferentemente da estimativa das duas metades, não necessita de correções (CARDOSO, 2001, p.81).

Com relação ao critério para significância de Fatores de Carregamento, neste momento, deve-se tomar cuidado para se realizar considerações válidas a respeito dos fatores de carregamento. Hair et al (2005, p.107), apresentam três sugestões para ajudar a interpretação de fatores de carregamento:

- A primeira sugestão é de significância prática apenas. Fatores de carregamento maiores que 0,30 são considerados mínimos; carregamentos acima de 0,40 considerados muito importantes; e se os carregamentos superam 0,50, são considerados praticamente significantes. Isso significa dizer se um fator explica, pelo menos, $10 \%$ da variância total da variável (fator de carregamento aproximado de 0,30 ), ele é considerado significativo em um nível mínimo (fator de carregamento de 0,50 equivale a $25 \%$ da variância total da variável). O que um pesquisador deve ter em mente é que fatores de carregamento extremamente altos (0,80 e acima) não são típicos e o critério mais importante é a significância prática dos carregamentos, não a ênfase estatística. (HAIR et al., 2005).

- A segunda sugestão é mais conservadora que a anterior e refere-se ao nível de significância para a interpretação do fator de carregamento. Hair et al (2005) apresenta uma tabela com níveis restritos para servir de guia de estudos com fatores de carregamento significantes (Tabela 1). 
Tabela 1 - Guia para identificar fatores de carregamento significantes baseados em tamanho da amostra

\begin{tabular}{|c|c|}
\hline Fator de Carregamento & $\begin{array}{c}\text { Tamanho de Amostra Necessária para } \\
\text { Significância }\end{array}$ \\
\hline 0,30 & 350 \\
\hline 0,35 & 250 \\
\hline 0,40 & 200 \\
\hline 0,45 & 150 \\
\hline $\mathbf{0 , 5 0}$ & $\mathbf{1 2 0}$ \\
\hline 0,55 & 100 \\
\hline 0,60 & 85 \\
\hline 0,65 & 70 \\
\hline 0,70 & 60 \\
\hline 0,75 & 50 \\
\hline
\end{tabular}

Fonte: Hair et al, 2009, p.116.

- Na terceira sugestão, diz que o número de variáveis inicialmente analisadas é também importante para decidir quais fatores de carregamento são significativos.

Também foi utilizado na análise dos dados do questionário o Índice de Importância Relativa (IIR), o qual vem sendo empregado para hierarquizar quesitos avaliados em uma grandeza entre 0 e 1 em algumas pesquisas do setor (SOUSA, 2008; EADIE et Al., 2013; MUHWEZI, ACAI e OTIM, 2014), para a avaliação das doze potencialidades dos fatores que dificultam o acesso ao financiamento à inovação, visando estabelecer um ranking entre eles, sendo o IIR definido pela equação:

$$
(\text { IIR })=\frac{\sum P_{-}}{A \times N}
$$

$0 \leq \mathrm{IIR} \leq 1$

Onde: $\mathrm{P}=$ é o peso dado para cada elemento pelos participantes, variando entre 1 e 5 nessa Escala Likert, em que 1 é o grau menos significativo, e 5 é o grau mais significativo;

$A$ = é o maior peso, que representa o grau mais significativo, neste caso de valor 5; e

$$
\mathrm{N} \text { = é o total da amostra (x entrevistados). }
$$

\section{RESULTADOS}

Nesta seção são apresentados os resultados obtidos com a aplicação da metodologia proposta. Inicialmente apresentam-se as variáveis listadas como relevantes pela equipe gerencial. Após, são expostos os resultados da seleção dessas variáveis e, por sua vez, mostra a aplicação da AED. Na sequência, são apresentados os índices de precificação criados e o impacto dos mesmos na precificação. Por fim, é realizada uma discussão acerca do método de precificação proposto. 
Foi levantado todos os editais lançados pela FAPERJ (2010-2014). Os dados levantados foram extraídos do próprio site da Agência, ao todo foram 75 linhas de programas diferenciados, cujo valor aproximado financeiro disponibilizado ao mercado do estado do Rio de Janeiro é da ordem de R\$996. 382.918,40, sendo classificado na modalidade de Financiamento não reembolsável.

A elaboração do mapeamento de todos os programas lançados ocorreu com o intuito de auxiliar no agrupamento de oportunidades em quatro categorias de áreas de atuação: Inovação, Engenharia Civil (Construção Civil), Tecnologia da Informação (TI) e outros. Onde a categoria "Outros" abrange os editais que não contemplam a questão da inovação, engenharia civil ou TI. Desta forma, tem-se como mensurar, de maneira aproximada, as oportunidades destinadas a estes agrupamentos, conforme a Tabela 2, que mostra em volume o financeiro por ano.

Tabela 2 - Categorias de áreas de atuação - Editais FAPERJ (2010-2014)

\begin{tabular}{|c|c|c|c|c|c|c|}
\hline Programas FAPERJ (2010 - 2014) - Total & 2010 (RS) & 2011 (R\$) & 2012 (RS) & $2013(\mathrm{R} \$)$ & 2014 (RS) & $2010-2014$ (RS) \\
\hline Inovação e/ou (C.C., TI, Outros) & $55.750 .000,00$ & $43.220 .000,00$ & $30.060 .000,00$ & $131.761 .200,00$ & $67.100 .000,00$ & $327.891 .200,00$ \\
\hline Engenharia Civil (Construção Civil) & $107.262 .000,00$ & $135.409 .000,00$ & $90.824 .600,00$ & $180.401 .200,00$ & $188.950 .118,40$ & $702.846 .918,40$ \\
\hline Tecnologia da Informação(TI) & $2.500 .000,00$ & & $2.500 .000,00$ & $25.000 .000,00$ & $2.500 .000,00$ & $32.500 .000,00$ \\
\hline \multirow[t]{2}{*}{ Outros } & $42.782 .800,00$ & $34.082 .000,00$ & $40.646 .400,00$ & $102.046 .400,00$ & $58.477 .600,00$ & $278.035 .200,00$ \\
\hline & $208.294 .800,00$ & $212.711 .000,00$ & $164.031 .000,00$ & $439.208 .800,00$ & $317.027 .718,40$ & \\
\hline
\end{tabular}

Fonte: Os autores (2016).

Também foi realizado o levantamento, por projeto contemplado, por cada edital lançado, com o intuito de aferir as áreas de conhecimento que vêm obtendo mais sucesso no financiamento dos seus projetos submetidos junto à agência de fomento FAPERJ (2010 - 2014), onde podemos verificar a baixa adesão da engenharia civil.

Das 75 linhas de programas da FAPERJ, não foi possível identificar os contemplados e classificar suas respectivas áreas de conhecimento, dos seguintes programas: Apoio à inovação e difusão tecnológica no Estado do Rio de Janeiro; Apoio ao desenvolvimento de modelos de inovação tecnológica e social; Bolsa nota 10; e Equipamento solidário - CAPES/FAPERJ.

Então, nos demais programas, foram mapeados todos os projetos contemplados dentro do período 2010-2014 e, dessa forma, foi possível averiguar quais áreas de conhecimento estão obtendo, com mais frequência, o financiamento ofertado pela FAPERJ. Ao todo foram identificados 7575 projetos. Como não há classificação de área de conhecimento no resultado divulgado pela FAPERJ em seu site, foi gerada essa classificação, utilizando as áreas de conhecimento que a CAPES sancionou, em primeiro nível. Apenas na área de conhecimento das engenharias a classificação entra em um segundo nível, para possibilitar não só a verificação do volume em percentual dos projetos contemplados pelas engenharias, mas também averiguar como a engenharia civil vem despontando sob essa questão do financiamento junto à Agência. 
Tabela 3 - Áreas de conhecimento x \% de projetos contemplados - FAPERJ (2010-2014)

\begin{tabular}{|l|c|}
\hline Área de Conhecimento & $\begin{array}{l}\text { \% De Projetos } \\
\text { Contemplados }\end{array}$ \\
\hline Ciências Agrárias & 8,09 \\
Ciências Biológicas & 6,56 \\
Ciências da Saúde & 28,01 \\
Ciências Exatas e da Terra & 10,98 \\
Ciências Humanas & 22,19 \\
Ciências Sociais Aplicadas & 6,72 \\
Engenharias & $\mathbf{1 1 , 1 0}$ \\
Linguística, Letras e Artes & 5,24 \\
Outros & 1,09 \\
\hline
\end{tabular}

Fonte: Os autores (2016).

Como mostra a Tabela 3, dentre os contemplados nos projetos financiados pela FAPERJ, podemos verificar que a área das ciências da saúde com $28,01 \%$ é a que mais obteve financiamento, em segundo lugar está a área de ciências humanas com 22,19\% e em terceiro lugar a área das Engenharias com 11,10\%. Nas Engenharias foram contemplados 841 projetos e destes a engenharia civil obteve 85 contemplações. Dentre a margem total possível de oportunidades, a Engenharia Civil perfaz um total de 1,12\% dos projetos contemplados, o que podemos considerar um valor pouco representativo, como pode ser visto na Tabela 4.

Tabela 4 - Áreas de Engenharia x \% de projetos contemplados - FAPERJ (2010-2014)

\begin{tabular}{|l|c|}
\hline \multicolumn{1}{|c|}{ Área de Conhecimento da Engenharia } & $\begin{array}{c}\text { \% De Projeto } \\
\text { Contemplado }\end{array}$ \\
\hline Engenharia de Produção & 3,23 \\
Engenharia Química & 1,75 \\
Engenharia Civil & $\mathbf{1 , 1 2}$ \\
Engenharia Sanitária & 1,04 \\
Engenharia Elétrica & 0,94 \\
Engenharia de Materiais e Metalúrgica & 0,84 \\
Engenharia Biomédica & 0,80 \\
Engenharia Mecânica & 0,73 \\
Engenharia de Transporte & 0,18 \\
Engenharia Nuclear & 0,18 \\
Engenharia Aeroespacial & 0,11 \\
Engenharia de Minas & 0,07 \\
Engenharia Naval e Oceânica & 0,06 \\
\hline
\end{tabular}

Fonte: Os autores (2016).

\section{Aplicação e validação do survey}

Para se entender quais as possíveis dificuldades de acesso ao financiamento junto à Agência, foi desenvolvido um survey (questionários preliminar e definitivo). O questionário preliminar foi aplicado com o objetivo de captar dos profissionais respondentes cinco fatores críticos que eles acreditavam dificultar o acesso ao financiamento à inovação. Da totalidade dos 108 respondentes do 
questionário preliminar, $62,9 \%$ já submeteram pelo menos 1 projeto para obter financiamento de alguma agência de fomento do Brasil. Além disso, foi possível consolidar nas respostas os 12 fatores considerados como sendo os mais críticos, conforme pode ser visto na Tabela 5.

Tabela 5 - Fatores críticos resultantes da aplicação do questionário preliminar

\begin{tabular}{|c|c|c|}
\hline & Fatores que dificultam acesso aos financiamentos ofertado pelos órgãos de fomento à inovação no RJ & $\begin{array}{l}\text { Número de vezes } \\
\text { citado pelos } \\
\text { entrevistados }\end{array}$ \\
\hline VAR1 & $\begin{array}{l}\text { Burocracia excessiva em todo processo: submissão do projeto, prestação de contas, comprovação sobre } \\
\text { a inovação criada e etc.; }\end{array}$ & 48 \\
\hline VAR2 & $\begin{array}{l}\text { Ausência de uma divulgação mais ampla dos editais por parte das agências de fomento à sociedade, } \\
\text { área acadêmica e aos empresários; }\end{array}$ & 41 \\
\hline VAR3 & $\begin{array}{l}\text { Problemas de suporte por parte da agência financiadora: acesso ao edital, carência de profissionais da } \\
\text { agência que orientem de forma adequada sobre as dúvidas referentes aos editais, morosidade na } \\
\text { divulgação dos resultados e etc.; }\end{array}$ & 36 \\
\hline VAR4 & $\begin{array}{l}\text { Problemas com relação ao aspecto financeiro: o valor disponível nos editais é baixo para a execução de } \\
\text { projetos, atrasos na liberação da verba contemplada, discrepância entre o valor pleiteado no projeto } \\
\text { (necessário) e o valor liberado ao projeto após a sua aprovação e etc.; }\end{array}$ & 31 \\
\hline VAR5 & $\begin{array}{l}\text { Falta de uma classificação mais clara do que realmente é considerado inovação no edital, expectativa de } \\
\text { retorno rápido na geração da inovação; }\end{array}$ & 27 \\
\hline VAR6 & $\begin{array}{l}\text { Falta de profissionais preparados para elaboração dos projetos a serem submetidos, realizarem a } \\
\text { prestação de contas e etc.; }\end{array}$ & 26 \\
\hline VAR7 & $\begin{array}{l}\text { Falta de interesse dos empresários em gerar contribuições inovadoras, interação do meio empresarial, } \\
\text { acadêmico e governamental ainda insuficiente para gerar interesse em participar do edital e etc.; }\end{array}$ & 16 \\
\hline VAR8 & Falta de profissionais operacionais preparados para implementar o projeto; & 12 \\
\hline VAR9 & $\begin{array}{l}\text { Legislação destinada à inovação muito complexa desestimulando a participação nos projetos e obtenção } \\
\text { de financiamento; }\end{array}$ & 12 \\
\hline VAR10 & Editais de inovação comáreas muito específicas por ex. gás, petróleo, saúde e TI; & 11 \\
\hline VAR1 1 & $\begin{array}{l}\text { Carência de profissionais de alto valor agregado (doutores) disponíveis a compor os grupos de trabalho } \\
\text { (coordenadores) conforme exigência dos editais; poucos grupos disponíveis a criar network de } \\
\text { conhecimento e equipamentos; }\end{array}$ & 10 \\
\hline VAR12 & Poucos editais destinados à inovação. & 9 \\
\hline
\end{tabular}

Fonte: Os autores (2016).

No segundo momento, elaborou-se o questionário definitivo, com o objetivo de confirmar a existência dos 12 tipos de dificuldades (fatores críticos) citadas pelos profissionais. Utilizou-se a escala Likert para aferir o instrumento, cada fator crítico identificado foi transformado em uma assertiva, sendo considerado como uma variável a ser analisada.

A segunda parte da survey (questionário definitivo), aplicada para aferir a confiabilidade das 12 variáveis identificadas (dificuldades), foi respondida por 131 profissionais, com exclusão de 8 por inconsistência em suas respostas, conforme Tabela 6. 
Tabela 6 - Resumo do processamento de caso

\begin{tabular}{|c|c|c|c|}
\hline & & $\mathbf{N}$ & $\%$ \\
\hline \multirow{3}{*}{ Casos } & Válido & 123 & 93,9 \\
\hline & Excluídos & 8 & 6,1 \\
\hline & Total & 131 & 100,0 \\
\hline
\end{tabular}

Fonte: Os autores (2016).

Iniciou-se a análise do instrumento, verificando sua validade de conteúdo, seguido da confiabilidade, através da utilização do Alfa de Cronbach e da validação do constructo.

A validade do conteúdo foi verificada através da frequência de perdas de dados, ou seja, perguntas não respondidas ou aquelas assinaladas na escala NE (Não entendi a afirmação). No questionário definitivo, que se trata da verificação da aderência das 12 variáveis (dificuldades), não houve uma perda significativa, pois apenas 8 profissionais deixaram de responder a essas questões, ou seja, cerca de $6,1 \%$, que é um valor menor do que os $10 \%$ que serve de parâmetro de aceitação. Então, em termos de validade do conteúdo, as 12 variáveis realmente são válidas.

A confiabilidade foi obtida através da consistência interna das variáveis, com base no coeficiente Alfa de Cronbach, calculado por meio do software SPSS. Foram considerados aceitáveis os constructos com Alfa de Cronbach, preferencialmente, superior a 0,70. Na Tabela 7 o valor do Alfa de Cronbach $(0,867)$ ficou bem superior ao mínimo aceitável para as 12 variáveis.

Tabela 7 - Estatísticas de confiabilidade

\begin{tabular}{|r|r|r|}
\hline $\begin{array}{c}\text { Alfa de } \\
\text { Cronbach }\end{array}$ & $\begin{array}{c}\text { Alfa de Cronbach } \\
\text { com base em itens } \\
\text { padronizados }\end{array}$ & N de itens \\
\hline, 864 &, 867 & 12 \\
\hline
\end{tabular}

$\mathrm{Na}$ validação do principal constructo, "Fatores que dificultam acesso aos financiamentos ofertado pelos órgãos de fomentos à inovação no RJ", foi realizada pela análise fatorial, para a verificação se existem grupos de assertivas a serem considerados, ou se a resposta ao questionário configura a existência de apenas um único Fator.

Inicialmente foi realizado os testes KMO e Bartlett's. O valor obtido do Teste KMO foi de 0,837 , superior ao mínimo necessário de 0,5 , indicando que a análise fatorial é apropriada aos dados estudados. O teste de Esfericidade de Bartletts's foi considerado altamente significativo, com p-valor de 0,000, que é inferior ao mínimo necessário de 0,001, confirmando a adequação da análise fatorial, conforme Tabela 8. 
Tabela 8 - Teste de KMO e BARTLETT

\begin{tabular}{|c|c|c|}
\hline \multicolumn{2}{|c|}{ Medida Kaiser-Meyer-Olkin de adequação de amostragem. } & $\begin{array}{r}, 837 \\
601,025\end{array}$ \\
\hline Teste de esfericidade de Bartlett & df & 66 \\
\hline & Sig. & 000 \\
\hline
\end{tabular}

Fonte: Os autores (2016).

Na Tabela 9 tem-se o fator de carregamento de cada variável considerada no principal constructo. Após a análise desses dados, é possível verificar que, em geral, os valores dos fatores de carregamentos obtidos podem ser considerados adequados, confirmando a existência de apenas um Fator que represente o constructo estudado "Dificuldades de acesso ao financiamento junto à Agência de fomento do RJ". Apenas o fator crítico (Variável) 12 obteve um fator de carregamento de 0,498, porém seu valor está infimamente distante de 0,50, sendo considerado também válido.

Tabela 9 - Fatores de carregamento das variáveis

\begin{tabular}{|l|r|r|}
\hline & \multicolumn{1}{|c|}{ Inicial } & \multicolumn{1}{|c|}{ Extração } \\
\hline VAR01 & 1,000 &, 504 \\
VAR02 & 1,000 &, 579 \\
VAR03 & 1,000 &, 715 \\
VAR04 & 1,000 &, 625 \\
VAR05 & 1,000 &, 532 \\
VAR06 & 1,000 &, 658 \\
VAR07 & 1,000 &, 726 \\
VAR08 & 1,000 &, 710 \\
VAR09 & 1,000 &, 564 \\
VAR10 & 1,000 &, 808 \\
VAR11 & 1,000 &, 632 \\
VAR12 & 1,000 &, 498 \\
\hline
\end{tabular}

Fonte: Os autores (2016).

Uma outra informação que deve ser destacada é o tamanho da amostra analisada nesta pesquisa. Obteve-se 123 respondentes válidos, acima de 120, que é o parâmetro de aceitação definido por Hair et al (2005, p. 107).

Foi também realizada uma análise dos doze fatores críticos do principal constructo para o acesso ao financiamento junto à Agência de fomento, para verificar se existem agrupamentos mais específicos a serem considerados. Para isso, foi feita uma verificação das doze variáveis por meio da Análise Fatorial.

Verificou-se com os dados das variáveis que compõem o constructo, que elas constituem três Fatores, tendo em vista que existem três autovalores $(5,013$; 1,$465 ; 1,072$ ) que são superiores a 1,00, conforme Tabela 10. 
Tabela 10: Método de extração (Análise do componente principal)

\begin{tabular}{|c|c|c|c|c|c|c|c|c|c|}
\hline \multirow[b]{2}{*}{ Componente } & \multicolumn{3}{|c|}{ Valores próprios iniciais } & \multicolumn{3}{|c|}{$\begin{array}{c}\text { Somas de extração de } \\
\text { carregamentos ao quadrado }\end{array}$} & \multicolumn{3}{|c|}{$\begin{array}{c}\text { Somas rotativas de carregamentos } \\
\text { ao quadrado }\end{array}$} \\
\hline & Total & $\begin{array}{c}\% \text { de } \\
\text { variância }\end{array}$ & $\begin{array}{c}\% \\
\text { cumulativa }\end{array}$ & Total & $\begin{array}{c}\% \text { de } \\
\text { variância }\end{array}$ & $\begin{array}{c}\% \\
\text { cumulativa }\end{array}$ & Total & $\begin{array}{c}\text { \% de } \\
\text { variância }\end{array}$ & $\begin{array}{c}\% \\
\text { cumulativa }\end{array}$ \\
\hline 1 & 5,013 & 41,778 & 41,778 & 5,013 & 41,778 & 41,778 & 2,624 & 21,87 & 21,87 \\
\hline 2 & 1,465 & 12,204 & 53,982 & 1,465 & 12,204 & 53,982 & 2,501 & 20,839 & 42,709 \\
\hline 3 & 1,072 & 8,932 & 62,914 & 1,072 & 8,932 & 62,914 & 2,425 & 20,205 & 62,914 \\
\hline 4 & 0,868 & 7,23 & 70,144 & & & & & & \\
\hline 5 & 0,796 & 6,635 & 76,779 & & & & & & \\
\hline 6 & 0,598 & 4,986 & 81,764 & & & & & & \\
\hline 7 & 0,593 & 4,945 & 86,709 & & & & & & \\
\hline 8 & 0,394 & 3,283 & 89,992 & & & & & & \\
\hline 9 & 0,374 & 3,113 & 93,105 & & & & & & \\
\hline 10 & 0,299 & 2,494 & 95,599 & & & & & & \\
\hline 11 & 0,273 & 2,278 & 97,877 & & & & & & \\
\hline 12 & 0,255 & 2,123 & 100 & & & & & & \\
\hline
\end{tabular}

Fonte: Os autores (2016).

Após a verificação da existência de três fatores (Tabela 10), que consideramos três subconstructos, passou-se a identificar as variáveis que estavam agrupadas em cada um desses subconstructos. Para isso, foi realizada uma rotação ortogonal, de forma a proporcionar melhor agrupamento das variáveis. A Tabela 11 apresenta o agrupamento das variáveis dentro de cada subconstructo. Fica claro que os agrupamentos são: Subconstructo 1: Variáveis 1, 2, 3 e 4; Subconstructo 2: Variáveis 6, 7, 8 e 11; Subconstructo 3: Variáveis 5, 9, 10 e 12 .

Tabela 11 - Método de extração (Análise do componente principal) Método de rotação (Varimax com normalização de Kaiser)

\begin{tabular}{|l|r|r|r|}
\hline & \multicolumn{3}{|c|}{ Componente } \\
\cline { 2 - 4 } & 1 & \multicolumn{1}{|c|}{2} & \multicolumn{1}{c|}{3} \\
\hline VAR01 & 0,701 & $-0,062$ & $-0,089$ \\
VAR02 & 0,635 & 0,232 & 0,349 \\
VAR03 & 0,752 & 0,266 & 0,281 \\
VAR04 & 0,734 & 0,179 & 0,234 \\
VAR05 & 0,405 & 0,115 & 0,596 \\
VAR06 & 0,319 & 0,642 & 0,378 \\
VAR07 & 0,088 & 0,846 & $-0,046$ \\
VAR08 & 0,226 & 0,785 & 0,207 \\
VAR09 & 0,341 & 0,258 & 0,617 \\
VAR10 & $-0,037$ & 0,123 & 0,889 \\
VAR11 & $-0,037$ & 0,665 & 0,434 \\
VAR12 & 0,426 & 0,242 & 0,508 \\
\hline
\end{tabular}

Fonte: Os autores (2016). 
Assim, os Fatores identificados foram classificados em três Subconstructos preponderantes, sendo compostos por 4 variáveis cada Subconstructo.

No primeiro Subconstructo (Quadro 1), podemos identificar os "Problemas inerentes à Agência de fomento" (VAR1, VAR2, VAR3 e VAR4).

Quadro 1 - Subconstructo 1

\begin{tabular}{|c|c|c|c|}
\hline $\begin{array}{l}\text { 1- Burocracia excessiva em todo } \\
\text { processo: Submissão do projeto; } \\
\text { Prestação de contas; } \\
\text { Comprovação sobre a inovação } \\
\text { criada e etc. }\end{array}$ & $\begin{array}{l}\text { 2- Ausência de uma divulgação } \\
\text { mais ampla dos editais por parte } \\
\text { das agências de fomento à: } \\
\text { Sociedade; Área acadêmica e aos } \\
\text { Empresários. }\end{array}$ & $\begin{array}{l}3 \text { - Problemas de suporte por parte da } \\
\text { agência financiadora: Acesso ao edital; } \\
\text { Carência de profissionais da agência que } \\
\text { orientem de forma adequada sobre as } \\
\text { dúvidas referentes aos editais; } \\
\text { Morosidade na divulgação dos } \\
\text { resultados e etc. }\end{array}$ & $\begin{array}{l}4 \text { - Problemas com relação ao aspecto } \\
\text { financeiro: O valor disponível nos editais } \\
\text { são baixos para a execução de projetos; } \\
\text { Atraso na liberação da verba } \\
\text { contemplada; Discrepância entre o valor } \\
\text { solicitado no projeto (Necessário) e o } \\
\text { Valor liberado ao projeto após a sua } \\
\text { aprovação e etc. }\end{array}$ \\
\hline
\end{tabular}

Fonte: Os autores (2016).

No segundo Subconstructo (Quadro 2), podemos identificar os "Problemas relacionados aos profissionais" (VAR6, VAR7, VAR8 e VAR11).

Quadro 2 - Subconstructo 2

\begin{tabular}{|l|l|l|l|}
\hline $\begin{array}{l}\text { 5- Falta de uma classificação mais } \\
\text { clara do que realmente é } \\
\text { considerado inovação no edital; } \\
\begin{array}{l}\text { Expectativa de retorno rápido na } \\
\text { geração da inovação e etc. }\end{array}\end{array}$ & $\begin{array}{l}\text { - Legislação destinada à inovação } \\
\text { muito complexa: Desestimulando a } \\
\text { participação nos projetos e } \\
\text { obtenção de financiamento. }\end{array}$ & $\begin{array}{l}\text { 10 - Editais de inovação comáreas } \\
\text { muito específicas: Por ex. Gás, } \\
\text { Petróleo, Saúde e TI. }\end{array}$ & $\begin{array}{l}\text { 12 - Poucos editais } \\
\text { destinados à inovação. }\end{array}$ \\
\hline
\end{tabular}

Fonte: Os autores (2016).

No terceiro Subconstructo, podemos identificar os "Problemas relacionados aos Editais - Agência e Legislação" (VAR5, VAR9, VAR10 e VAR12).

Quadro 3 - Subconstructo 3

\begin{tabular}{|c|c|c|c|}
\hline $\begin{array}{l}\text { 6-Falta de profissionais preparados: } \\
\text { Para elaboração dos projetos a serem } \\
\text { submetidos; Realizarema prestação de } \\
\text { contas e etc. }\end{array}$ & $\begin{array}{l}\text { 7- Falta de interesse dos empresários } \\
\text { em gerar contribuições inovadoras: } \\
\text { Interação do meio empresarial, } \\
\text { acadêmico e governamental ainda } \\
\text { insuficiente para gerar interesse em } \\
\text { participar dos editais e etc. }\end{array}$ & $\begin{array}{l}\text { 8- Falta de profissionais operacionais } \\
\text { preparados para implementar o projeto. }\end{array}$ & $\begin{array}{l}11 \text { - Carência de profissionais de alto valor agregado } \\
\text { (Douttores) disponiveis a compor os grupos de } \\
\text { trabalho (Coordenadores) conforme a exigência dos } \\
\text { editais; Poucos grupos disponiveis a criar network } \\
\text { de conhecimento/equipamentos e etc. }\end{array}$ \\
\hline
\end{tabular}

Fonte: Os autores (2016).

Para vermos a pertinência desse resultado, precisaremos fazer, então, a análise de cada um dos três Subconstructos identificados.

Inicialmente, no Subconstructo 1 , foi verificado que apenas $4,6 \%$ dos pesquisados deixaram de responder à questão (Problemas inerentes à Agência de fomento). Como foi obtido um valor inferior a $10 \%$, pode-se garantir que o constructo possui validade de conteúdo. 
Tabela 12 - Resumo do processamento de caso - Subconstructo 1

\begin{tabular}{|cc|c|c|}
\hline & & N & $\%$ \\
\hline \multirow{4}{*}{ Casos } & Válido & 125 & 95,4 \\
& Excluídos & 6 & 4,6 \\
& Total & 131 & 100,0 \\
\hline
\end{tabular}

Fonte: Os autores (2016).

Posteriormente, para avaliar a validade do Subconstructo 1, Problemas inerentes à Agência de fomento, foi calculada a confiabilidade dos dados, baseando-se na inter-relação das variáveis que o compõem (VAR1, VAR2, VAR3 e VAR4). A confiabilidade calculada foi de 0,762 , ou seja, superior a 0,70 , o que garante a adequada inter-relação entre as variáveis que compõem o Subconstructo 1.

Tabela 13 - Estatísticas de confiabilidade

Subconstructo 1

\begin{tabular}{|c|c|c|}
\hline Alfa de Cronbach & $\begin{array}{c}\text { Alfa de Cronbach } \\
\text { com base em itens } \\
\text { padronizados }\end{array}$ & N de itens \\
\hline, 757 &, 762 & 4 \\
\hline
\end{tabular}

Fonte: Os autores (2016).

Com a confiabilidade assegurada, passou-se a realizar a análise fatorial. O resultado do Teste KMO foi de 0,716 (Tabela 14), mostrando que a aplicação da análise fatorial tem validade para as variáveis escolhidas, pois gera fatores distintos e confiáveis. O Teste de Esfericidade de Bartlett teve o $\mathrm{p}$-valor menor que 0,000 , demonstrando que as variáveis estão correlacionadas com a população. Dessa forma, a aplicação da Análise de Fator é adequada aos dados.

Tabela 14 - Teste de KMO e BARTLETT - Subconstructo 1

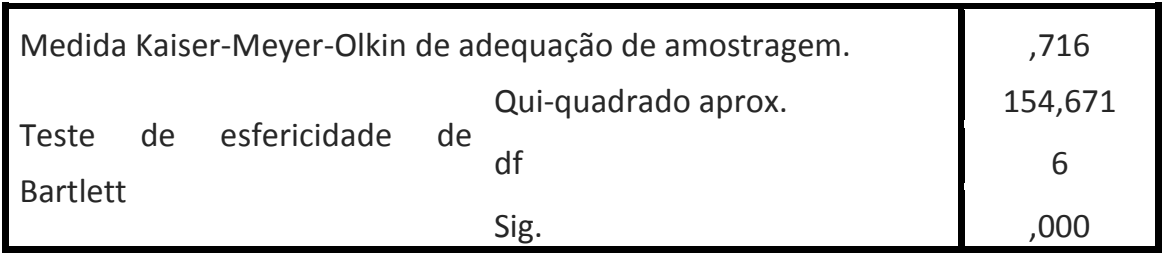

Fonte: Os autores (2016).

Verificou-se com os dados das variáveis que compõem o Subconstructo 1, que elas constituem um único Fator, ou seja, as variáveis que representam o Subconstructo 1 "Problemas inerentes à Agência de fomento", tendo em vista que só existe um Fator cujo autovalor $(2,384)$ é superior a 1,00 . 
Tabela 15 - Método de extração - Subconstructo 1 (Análise do componente principal)

\begin{tabular}{|c|c|c|c|c|c|c|}
\hline \multirow{2}{*}{ Componente } & \multicolumn{3}{|c|}{ Valores próprios iniciais } & \multicolumn{3}{c|}{$\begin{array}{c}\text { Somas de extração de } \\
\text { carregamentos ao quadrado }\end{array}$} \\
\cline { 2 - 7 } & Total & $\begin{array}{c}\text { \% de } \\
\text { variância }\end{array}$ & $\begin{array}{c}\% \\
\text { cumulativa }\end{array}$ & Total & $\begin{array}{c}\text { \% de } \\
\text { variância }\end{array}$ & $\begin{array}{c}\% \\
\text { cumulativa }\end{array}$ \\
\cline { 2 - 7 } & 2,384 & 59,6 & 59,6 & 2,384 & 59,6 & 59,6 \\
2 & 0,846 & 21,144 & 80,743 & & & \\
3 & 0,48 & 11,997 & 92,74 & & & \\
4 & 0,29 & 7,26 & 100 & & & \\
\hline
\end{tabular}

Fonte: Os autores (2016).

Por sua vez, conforme pode ser visto na Matriz de Componentes da Tabela 16, os carregamentos de cada variável que compõem o Subconstructo 1 , foram todos superiores a 0,50 , o que nos permite concluir que os dados são confiáveis e válidos.

Tabela 16 - Método de extração (Análise do componente principal) Matriz de componente do Fator 1

\begin{tabular}{|c|c|}
\hline \multirow{2}{*}{} & Componente \\
\cline { 2 - 2 } & 1 \\
\hline VAR01 & 0,528 \\
VAR02 & 0,810 \\
VAR03 & 0,884 \\
VAR04 & 0,817 \\
\hline
\end{tabular}

Fonte: Os autores (2016)

Agora passaremos a discutir os resultados das estatísticas de cada variável. A Tabela 17 e o Gráfico 1 das variáveis que congregam o Subconstructo 1: "Problemas inerentes à Agência de fomento" mostram que os resultados ficaram todos acima de 4,0 (Média calculada), evidenciando que no instrumento de avaliação utilizado (questionário) representa a opção "concordo".

Desta forma, tem-se a VAR2 (Ausência de uma divulgação mais ampla dos editais por parte das agências de fomento à sociedade, área acadêmica e aos empresários) obteve o maior resultado, 4,37, bem próxima do valor máximo de 5,0 , que seria "Concordo Completamente", conforme escala Likert utilizada. Dentro desse Subconstructo 1, a pior avaliação coube à VAR1 (Burocracia excessiva em todo processo: Submissão do projeto, prestação de contas, comprovação sobre a inovação criada e etc.) foi a que obteve a pontuação de 4,02. Se fizermos uma comparação entre os três subconstructos, verifica-se que o Subconstructo 1 é o que possui a melhor avaliação, pois todos os resultados de suas 4 variáveis atingiram valores superiores a 4,0.

Isso demonstra que a Agência de Fomento deve ter muito cuidado na ampla divulgação dos editais, de forma a possibilitar a participação tanto de pessoas da área acadêmica, como de pessoas ligadas ao setor empresarial. Além disso, devese estar atento aos problemas de acesso ao edital, tanto na forma virtual, como em meios físicos, orientando adequadamente aqueles que buscam participar das chamadas e divulgando de forma célere os resultados finais. 
Tabela 17 - Estatística itens do Subconstructo 1

\begin{tabular}{|c|c|c|c|}
\hline & Média & Desvio padrão & N \\
\hline VAR01 & 4,02 & 1,132 & 125 \\
VAR02 & 4,37 &, 988 & 125 \\
VAR03 & 4,20 & 1,040 & 125 \\
VAR04 & 4,05 & 1,156 & 125 \\
\hline
\end{tabular}

Fonte: Os autores (2016).

Gráfico 1 - Pontuação das variáveis que compõem o Subconstructo 1

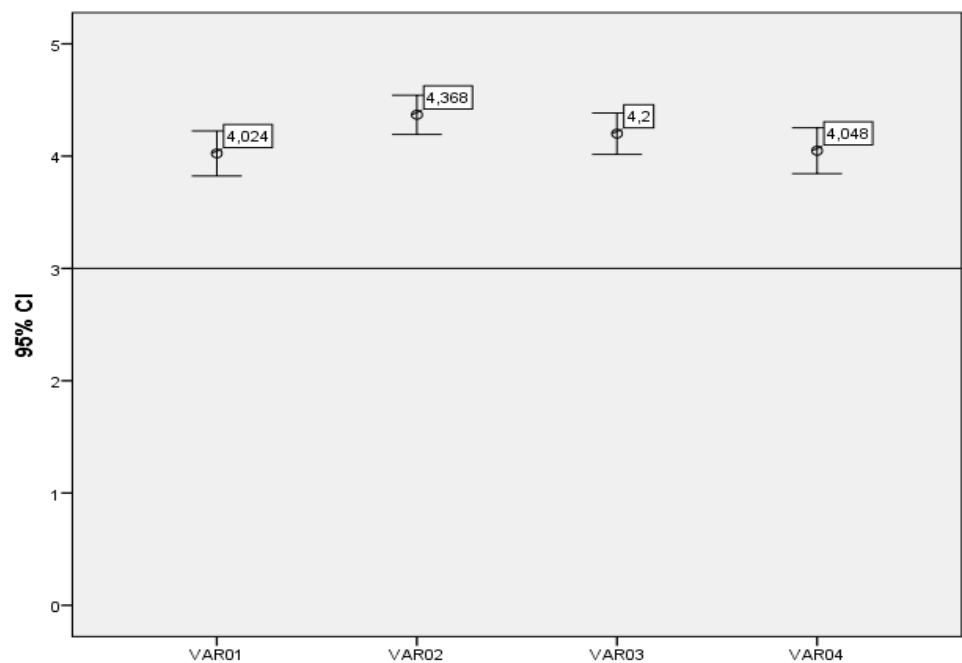

Fonte: Os autores (2016)

Em relação ao Subconstructo 2, foi verificado que, assim como no Subconstructo 1 , apenas $4,6 \%$ dos pesquisados deixaram de responder às assertivas (Problemas relacionados aos profissionais). Como foi obtido um valor inferior a $10 \%$, pode-se garantir que o constructo possui validade de conteúdo.

Tabela 18 - Resumo do processamento de caso - Subconstructo 2

\begin{tabular}{|cc|c|c|}
\hline & & N & $\%$ \\
\hline \multirow{3}{*}{ Casos } & Válido & 125 & 95,4 \\
& Excluídos & 6 & 4,6 \\
& Total & 131 & 100,0 \\
\hline
\end{tabular}

Fonte: Os autores (2016).

Em seguida, para avaliar a validade do Subconstructo 2, foi calculada a confiabilidade dos dados, baseando-se na inter-relação das variáveis que o compõem (VAR6, VAR7, VAR8 e VAR11). A confiabilidade calculada foi de 0,803 , ou seja, superior a 0,70 , o que garante a adequada inter-relação entre as variáveis que compõem o constructo. 
Tabela 19 - Estatísticas de confiabilidade - Subconstructo 2

\begin{tabular}{|c|c|c|}
\hline $\begin{array}{c}\text { Alfa de } \\
\text { Cronbach }\end{array}$ & $\begin{array}{c}\text { Alfa de Cronbach } \\
\text { com base em itens } \\
\text { padronizados }\end{array}$ & $\begin{array}{c}\text { N de } \\
\text { itens }\end{array}$ \\
\hline, 802 &, 803 & 4 \\
\hline
\end{tabular}

Fonte: Os autores (2016).

Após a verificação da confiabilidade assegurada, passou-se a realizar a análise fatorial. O resultado do Teste KMO foi de 0,769 (Tabela 20), mostrando que a aplicação da análise fatorial tem validade para as variáveis escolhidas, pois gera fatores distintos e confiáveis. O Teste de Esfericidade de Bartlett teve o $\mathrm{p}$ valor menor que 0,000 , demonstrando que as variáveis estão correlacionadas com a população. Dessa forma, a aplicação da Análise de Fator é adequada aos dados também para o Subconstructo 2 .

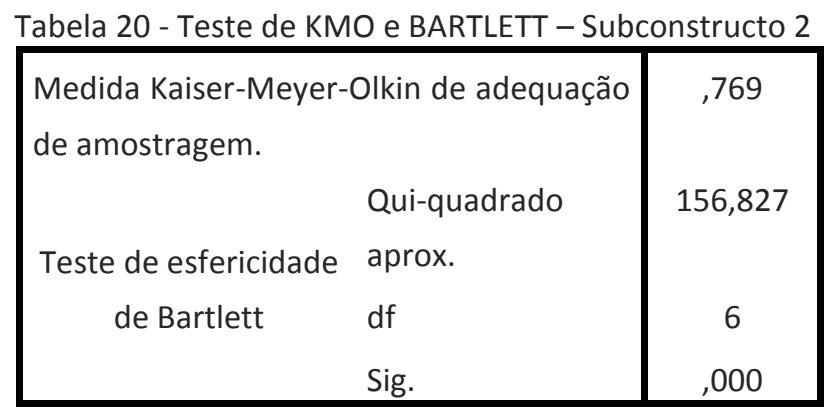

Fonte: Os autores (2016).

Constatou-se através dos dados das variáveis que compõem o Subconstructo 2 "Problemas relacionados aos profissionais" (Tabela 21), que elas constituem um único Fator, tendo em vista que só existe um autovalor $(2,522)$ que é superior a 1,00 .

Tabela 21 - Método de extração - Subconstructo 2 (Análise do componente principal)

\begin{tabular}{|c|c|c|c|c|c|c|}
\hline \multirow{2}{*}{ Componente } & \multicolumn{3}{|c|}{ Valores próprios iniciais } & \multicolumn{3}{c|}{$\begin{array}{c}\text { Somas de extração de } \\
\text { carregamentos ao quadrado }\end{array}$} \\
\cline { 2 - 7 } & Total & $\begin{array}{c}\% \text { de } \\
\text { variância }\end{array}$ & $\begin{array}{c}\% \\
\text { cumulativa }\end{array}$ & Total & $\begin{array}{c}\% \text { de } \\
\text { variância }\end{array}$ & $\begin{array}{c}\% \\
\text { cumulativa }\end{array}$ \\
\cline { 2 - 7 } & 2,522 & 63,041 & 63,041 & 2,522 & 63,041 & 63,041 \\
2 & 0,585 & 14,634 & 77,675 & & & \\
3 & 0,558 & 13,942 & 91,616 & & & \\
4 & 0,335 & 8,384 & 100 & & & \\
\hline
\end{tabular}

Fonte: Os autores (2016).

Na Matriz de Componentes da Tabela 22, os carregamentos de cada variável que compõem o Subconstructo 2 , foram todos superiores a 0,50 , o que nos permite concluir que os dados são confiáveis e válidos. 
Tabela 22 - Método de extração (Análise do componente principal) - Matriz de componente do Subconstructo 2

\begin{tabular}{|c|c|}
\hline \multirow{2}{*}{} & Componente \\
\cline { 2 - 2 } & 2 \\
\hline VAR06 & 0,812 \\
VAR07 & 0,754 \\
VAR08 & 0,856 \\
VAR11 & 0,749 \\
\hline
\end{tabular}

Fonte: Os autores (2016).

Ao ser discutido os resultados das estatísticas de cada variável, Tabela 23 e Gráfico 2 das variáveis que congregam o Subconstructo 2 "Problemas relacionados aos profissionais", observa-se que os resultados ficaram todos abaixo de 4,0, porém bem próximos deste valor.

A Tabela 23 mostra que a VAR6 (Falta de profissionais preparados para: elaboração dos projetos a serem submetidos, realizarem a prestação de contas, etc.), que é o melhor resultado do Subconstructo, possui o valor de 3,94, abaixo do valor 4,0, que seria "Concordo", conforme escala Likert utilizada. Dentro desse subagrupamento de variáveis que compõem o Subconstructo 2, a VAR11 "Carência de profissionais de alto valor agregado disponíveis a compor os grupos de trabalho conforme exigência dos editais, poucos grupos disponíveis para criar network de conhecimento e equipamentos" obteve o menor valor de toda a pesquisa, 3,72 .

Porém, analisando os 3 Subconstructos identificados e suas respectivas variáveis, o Subconstructo 2 possui as VAR8 e VAR11 que são as que receberam as piores avaliações dos respondentes. Ou seja, para eles, são as variáveis menos importantes.

Tabela 23 - Estatísticas de itens do Subconstructo 2

\begin{tabular}{|c|c|c|c|}
\hline & Média & Desvio padrão & N \\
\hline VAR06 & 3,94 & 1,131 & 125 \\
VAR07 & 3,89 & 1,145 & 125 \\
VAR08 & 3,74 & 1,151 & 125 \\
VAR11 & 3,72 & 1,248 & 125 \\
\hline
\end{tabular}

Fonte: Os autores (2016). 
Gráfico 2 - Níveis de carregamento das variáveis que compõem o Subconstructo 2

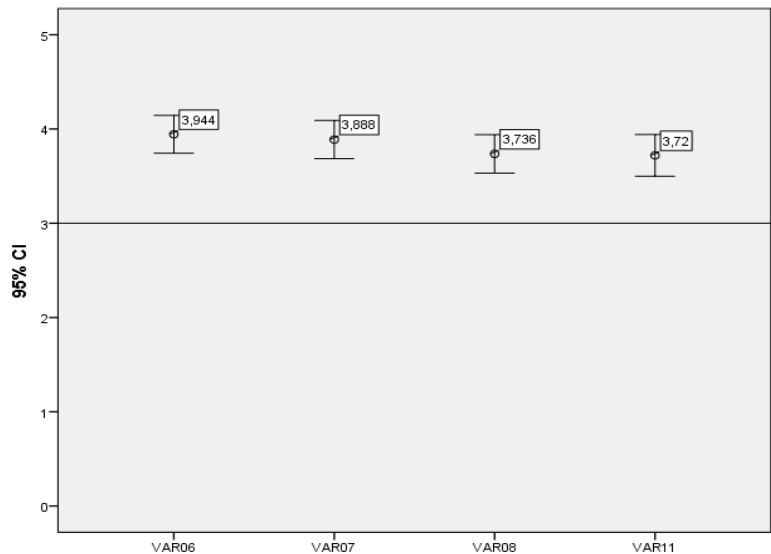

Fonte: Os autores (2016).

Ao que se refere a análise do Subconstructo 3, foi verificado que $2,3 \%$ dos pesquisados deixaram de responder à questão. Como foi obtido um valor inferior a $10 \%$, pode-se garantir que o constructo possui validade de conteúdo.

Tabela 24 - Resumo do processamento de caso - Subconstructo 3

\begin{tabular}{|rl|r|r|}
\hline & & N & \multicolumn{1}{|c|}{$\%$} \\
\hline \multirow{3}{*}{ Casos } & Válido & 128 & 97,7 \\
& Excluídos & 3 & 2,3 \\
& Total & 131 & 100,0 \\
\hline
\end{tabular}

Fonte: Os autores (2016).

O passo seguinte, para avaliar a validade do constructo Subconstructo 3 "Problemas relacionados aos Editais - Agência e Legislação", foi calculada a confiabilidade dos dados, baseando-se na inter-relação das variáveis que o compõem (VAR5, VAR9, VAR10 e VAR12). A confiabilidade calculada foi de 0,753, ou seja, superior a 0,70 , o que garante a adequada inter-relação entre as variáveis que compõem o constructo.

Tabela 25 - Estatísticas de confiabilidade - Subconstructo 3

\begin{tabular}{|c|c|c|}
\hline $\begin{array}{c}\text { Alfa de } \\
\text { Cronbach }\end{array}$ & $\begin{array}{c}\text { Alfa de Cronbach } \\
\text { com base em itens } \\
\text { padronizados }\end{array}$ & $\begin{array}{c}\text { N de } \\
\text { itens }\end{array}$ \\
\hline, 752 &, 753 & 4 \\
\hline
\end{tabular}

Fonte: Os autores (2016)

Com a constatação da confiabilidade ser realmente acima do valor mínimo requerido, passou-se a realizar a análise fatorial. O resultado do Teste KMO foi de 0,733 (Tabela 26), mostrando que a aplicação da análise fatorial tem validade para as variáveis escolhidas, pois gera fatores distintos e confiáveis. O Teste de Esfericidade de Bartlett teve o p-valor menor que 0,000, demonstrando que as variáveis estão correlacionadas com a população. Dessa forma, a aplicação da Análise de Fator é adequada aos dados. 
Tabela 26 - Teste de KMO e BARTLETT - Fator 3

\begin{tabular}{|c|c|c|}
\hline \multicolumn{2}{|c|}{ Medida Kaiser-Meyer-Olkin de adequação de amostragem. } & ,733 \\
\hline \multirow{3}{*}{$\begin{array}{l}\text { Teste de esfericidade de } \\
\text { Bartlett }\end{array}$} & Qui-quadrado aprox. & 118,469 \\
\hline & df & 6 \\
\hline & Sig. & 000 \\
\hline
\end{tabular}

Fonte: Os autores (2016).

Constatou-se na Tabela 27, com os dados das variáveis que compõem o constructo, que elas constituem um único Fator, ou seja, as variáveis representam o Subconstructo 3 "Problemas relacionados aos Editais - Agência e Legislação", tendo em vista que só existe um Fator cujo autovalor $(2,303)$ é superior a 1,00 .

Tabela 27 - Método de extração - Subconstructo 3 (Análise do componente principal)

\begin{tabular}{|c|c|c|c|c|c|c|}
\hline \multirow{2}{*}{ Componente } & \multicolumn{3}{|c|}{ Valores próprios iniciais } & \multicolumn{3}{c|}{$\begin{array}{c}\text { Somas de extração de } \\
\text { carregamentos ao quadrado }\end{array}$} \\
\cline { 2 - 7 } & Total & $\begin{array}{c}\% \text { de } \\
\text { variância }\end{array}$ & $\begin{array}{c}\% \\
\text { cumulativa }\end{array}$ & Total & $\begin{array}{c}\% \text { de } \\
\text { variância }\end{array}$ & $\begin{array}{c}\% \\
\text { cumulativa }\end{array}$ \\
\hline 1 & 2,303 & 57,565 & 57,565 & 2,303 & 57,565 & 57,565 \\
2 & 0,711 & 17,78 & 75,344 & & & \\
3 & 0,575 & 14,383 & 89,728 & & & \\
4 & 0,411 & 10,272 & 100 & & & \\
\hline
\end{tabular}

Fonte: Os autores (2016).

Com relação Matriz de Componentes, pode ser visto na Tabela 28, os carregamentos de cada variável que compõem o Subconstructo 3, foram todos superiores a 0,50 , o que nos permite concluir que os dados são confiáveis e válidos.

Tabela 28 - Método de extração (Análise do componente principal)

- Matriz de componente do Subconstructo 3

\begin{tabular}{|l|c|}
\hline \multirow{2}{*}{} & Componente \\
\cline { 2 - 2 } & 3 \\
\hline VAR05 & 0,704 \\
VAR09 & 0,817 \\
VAR10 & 0,764 \\
VAR12 & 0,745 \\
\hline
\end{tabular}

Fonte: Os autores (2016).

A seguir será detalhado os resultados das estatísticas de cada variável. A Tabela 29 e o Gráfico 3 das variáveis que congregam o Subconstructo 3 "Problemas relacionados aos Editais - Agência e Legislação" mostram que os resultados, em geral, ficaram muito próximos de 4,0 em 3 das variáveis (VAR5, VAR9 e VAR10) e em 1 (VAR12), ficou um pouco acima.

$\mathrm{Na}$ análise das estatísticas das variáveis do Subconstructo 3, a VAR12 "Poucos editais destinados à inovação", VAR 5 "Falta de uma classificação mais 
clara do que realmente é considerado inovação no edital" e VAR 9 "Legislação destinada à inovação muito complexa: Desestimulando a participação nos projetos e obtenção de financiamento" foram avaliadas em torno da 4,0, que seria o equivalente a "Concordo", conforme escala Likert utilizada. Dentro do Subconstructo 3, apenas a VAR10 "Editais de inovação com áreas muito específicas, por ex. gás, petróleo, saúde e TI" obteve uma avaliação de 3,83, menor do que 4,0 .

Esse Subconstructo 3 mostra o quanto foi considerado importante a existência de um profissional que auxilie na elaboração de projetos para serem submetidos aos órgãos de fomento, pois assim pode-se fazer frente às dificuldades relacionadas ao entendimento do edital e da legislação envolvida.

Tabela 29 - Estatísitca de itens do Fator 3

\begin{tabular}{|l|r|r|r|}
\hline & Média & $\begin{array}{r}\text { Desvio } \\
\text { padrão }\end{array}$ & \multicolumn{1}{c|}{$\mathrm{N}$} \\
\hline VAR05 & 3,97 & 1,064 & 128 \\
VAR09 & 3,97 & 1,086 & 128 \\
VAR10 & 3,83 & 1,224 & 128 \\
VAR12 & 4,02 & 1,053 & 128 \\
\hline
\end{tabular}

Fonte: Os autores (2016).

Gráfico 3 - Níveis de carregamento das variáveis que compõem o Subconstructo 3

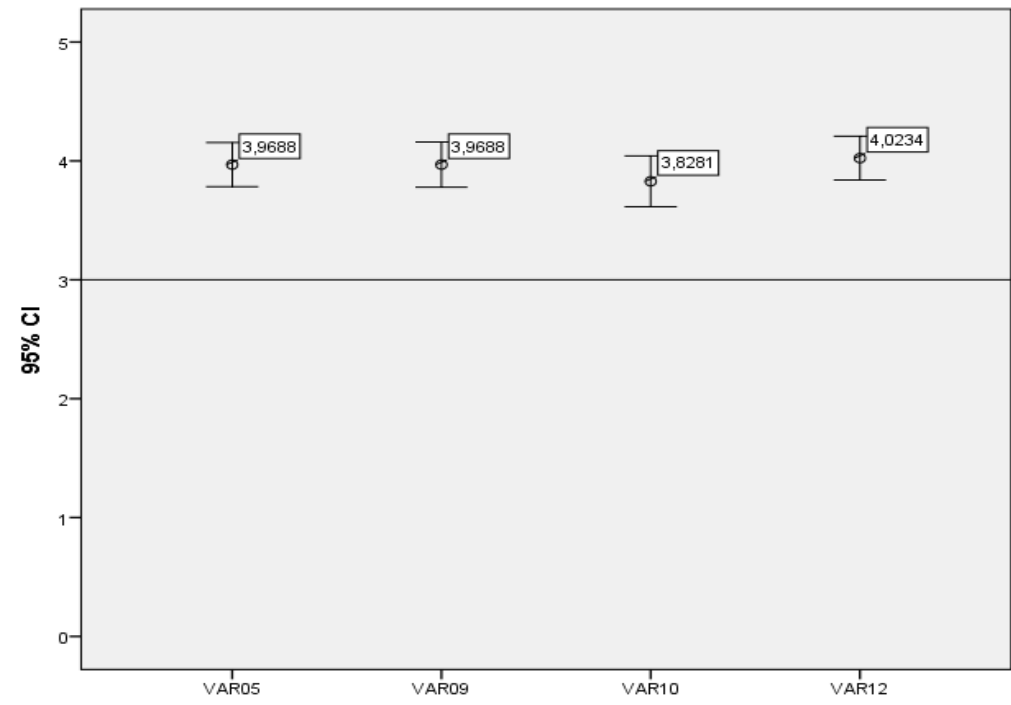

Fonte: Os autores (2016).

\section{CONCLUSÕES}

O objetivo de artigo foi apresentar os resultados da pesquisa realizada para identificar os fatores que dificultam acesso aos financiamentos ofertado pelos órgãos de fomento à inovação sob a ótica dos profissionais atuantes no mercado 
(Empresarial e/ou Acadêmico) e, dessa forma, entender a participação dos profissionais que atuam na Construção Civil, nesse contexto. Além disso, buscouse identificar a amplitude de oportunidades de financiamento da inovação para o setor de Construção Civil nos editais de fomento oferecidos pela FAPERJ.

Conforme a identificação de necessidades realizado pelo Programa Inovação Tecnológica, estruturado pela Câmara Brasileira da Indústria da Construção para o setor, foi observado vários pontos de carência de desenvolvimento, que precisam ser resolvidos ou pelo menos mitigados. Sendo a inovação um meio pelo qual a Construção Civil pode se destacar.

Dentre os mecanismos de estimulo à inovação, o estado do Rio de Janeiro vem buscando simplificar a inserção dos profissionais na questão do financiamento da inovação, por isso, pode ser considerado um fator muito positivo a aprovação da Lei no 13.243 de 11.01.2016, "Marco Regulatório de Ciência, Tecnologia e Inovação". Esta lei apresenta uma regulamentação menos burocrática aos tramites de incentivo à inovação ao País. Essa nova lei também traz uma concepção mais abrangente do que seja o termo "inovação". Isso vai ao encontro do Subconstructo 2 "Problemas relacionados aos profissionais", que demostrou que essa pode ser uma das principais carências para aqueles que buscam o financiamento da inovação.

Para se ter uma visão mais assertiva sob a participação do setor de Construção Civil na questão da busca por financiamento junto as agências de fomento, foi parametrizada a utilização de todos os editais da FAPERJ entre 2010 e 2014, onde conseguiu-se constatar uma baixa aderência da Engenharia Civil (Construção Civil) no processo de submissão e obtenção de fomento junto à Agência. Isso pode estar sendo provocado pelo Fator Crítico "Problemas com relação ao aspecto financeiro", pois para o setor de construção civil os valores disponíveis nos editais são considerados baixos para a execução de projetos.

Verificou-se o percentual de $1,11 \%$ dos projetos contemplados a fundo perdido, ou seja, financiamento não reembolsável, pelas empresas de Construção Civil, dentro do total de $11,01 \%$ de obtenção de projetos financiados pela Agência, pertinentes às áreas de conhecimento das Engenharias. A área que tem o maior percentual de projetos contemplados pela FAPERJ é de Ciências da Saúde com $28,01 \%$. Novamente o baixo valor ofertado por projeto pode estar afugentando os profissionais ligados ao setor de construção civil.

O mapeamento dos editais da Agência possibilitou ter uma visão mais clara sobre o volume aproximado financeiro disponível, onde concluímos ter uma margem grande de oportunidades onde as empresas de Construção Civil poderiam participar, tanto nos editais específicos direcionados à inovação, como em editais de outros tipos de financiamento.

Em um segundo momento, com a aplicação do survey, os questionários preliminar e definitivo, foi possível averiguar, no questionário preliminar, quais fatores os profissionais atuantes no financiamento da inovação consideravam importantes para a sua obtenção nas agências de fomento. Posteriormente, no questionário definitivo, foi averiguado quais os fatores considerados críticos para participar de projetos de inovação na FAPERJ.

Assim foram identificados 12 tipos de fatores críticos (dificuldades) relacionados ao constructo principal "Fatores que dificultam acesso aos 
financiamentos ofertado pela FAPERJ". Os mesmos foram validados, analisadas suas respectivas confiabilidades e constatadas as suas relevâncias, sendo verificado que todas são aplicáveis à realidade do mercado com relação ao constructo.

Como resultado gerado no SPSS, ainda se verificou através dos dados das variáveis (Fatores críticos) que compõem o constructo, que elas constituem três subconstructos com 4 componentes (variáveis) cada um. Cada subconstructo foi estruturado da seguinte forma: Problemas inerentes à Agência de fomento (VAR1, VAR2, VAR3 e VAR4), Problemas relacionados aos profissionais (VAR6, VAR7, VAR8 e VAR11) e Problemas relacionados aos Editais - Agência e Legislação (VAR5, VAR9, VAR10 e VAR12).

$\mathrm{Na}$ primeira categoria temos problemas que vão desde a burocracia excessiva até problemas com relação ao aspecto financeiro. O segundo subconstructo trata de questões de carência de profissionais capacitados a elaborarem o projeto a ser submetido a prestação de contas de forma correta perante à Agência. Neste subconstructo ainda ressalta a escassez de grupos de trabalho atuantes que possam fazer uma retroalimentação de informações, propiciando uma interação com o mercado. $O$ terceiro subconstructo abrange questões desde a necessidade de maturação do processo como um todo junto à Agência, assim como a necessidade de ser aumentado a quantidade de editais específicos à Inovação. 


\title{
The search for finance of innovation in construction industry - Rio de Janeiro
}

\begin{abstract}
The issue of the need to innovate is increasingly highlighted as the way by which countries there is the opportunity to add value to their respective economies. In addition to being necessary to solve such issues as the high volume of solid waste in construction. The objective was to observe the difficulties of access to finance by the Government Funding Agency. Through mapping the edicts issued from 2010 to 2014 and their contemplated projects, It was possible to obtain the classification of projects by field of knowledge, which made it possible ascertain that the Civil Engineering obtained funding from the Agency for only $1.12 \%$ of the total approved projects. A survey was applied to map 12 critical factors that hinder access to finance in this process. Reliability found was 0.867 , on content validation was found a loss of $6.10 \%$ where appears in the 12 valid critical factors. On construct validation, there is KMO Test with 0.837 and Bartlett's test of sphericity was 0.000 . Through the analysis of loading of critical factors proved the existence of a single construct, this being comprised of three subconstructos (Problems inherent in Funding Agency; Problems related to professional; and Problems relating to Publish - Agency and Legislation).
\end{abstract}

KEYWORDS: Innovation. Construction. Funding agencies. Line of funding. 


\section{REFERÊNCIAS}

ABRELPE. Panorama dos resíduos sólidos no Brasil - 2014. Disponível em: <http:// http://www.abrelpe.org.br/Panorama/panorama2014.pdf>. Acesso em: 08 set. 2016.

BRASIL. Plano Brasil Maior: Inovar para competir. Competir para crescer. Balanço Executivo (2011-2014). Disponível em:

<http://www.brasilmaior.mdic.gov.br/images/data/201411/f97a 720 83144d28b26013b7261e7e06b.pdf>. Acesso em: 20 dez. 2014.

BUENO, A.; TORKOMIAN, A. L. V. Financiamentos à inovação tecnológica: Reembolsáveis, Não Reembolsáveis e Incentivos Fiscais. Revista de Administração e Inovação, São Paulo, v.11, n.4, p.135-158, out. /dez. 2014.

BYRD, T. A. e TURNER, D. E. An exploratory examination of the relationship between flexible IT infrastructure and competitive advantage, Elsevier Science B.V., 2001.

CARDOSO, Rodolfo. Impacto das práticas-chave de melhoria da gestão (PCMG) no desempenho organizacional: Uma metodologia de avaliação. Dissertação de Mestrado em Sistemas e Computação, IME, Rio de Janeiro: 2001.

EXAME. Os 10 países mais inovadores do mundo. E o Brasil em 70․ setembro,2015. Disponível em:<http://exame.abril.com.br/tecnologia/noticias/os-10-paises-maisinovadores-do-mundo-e-o-brasil-em-70o>. Acesso em: 14 jul. 2016.

FAPERJ. Programas de apoio à ciência, tecnologia e inovação: Apoio à inovação tecnológica no Estado do Rio de Janeiro. Rio de Janeiro:2014. Disponível em: < http://www.faperj.br/downloads/livros/Inov_Tec_web.pdf>. Acesso em: 05 Abr. 2016.

FIELD, Andy. Factor Analysis using SPSS. 2.ed. London: Sage, 2005.

FIRJAN. Principais Linhas de Financiamento e Fomento para Inovação - 2015 Disponível em: $<$ http://www.firjan.com.br/lumis/portal/file/fileDownload.jsp?filed=2C908A8 A4E74DD64014E88446DA65E74>. Acesso em: 02 abr. 2016.

FURTADO, B. A. LIMA NETO, V. C.; KRAUSE, C. Estimativas do déficit habitacionais brasileiro (2007-2011) por municípios (2010). Brasília: Ipea, maio 2013. 
HAIR, J., ANDERSON, R., TATHAM, R., BLACK, W. Análise Multivariada de Dados. 5a Edição, Ed. Bookman, Porto Alegre:2005.

HAYES, B., Measuring Customer Satisfaction: Survey Design, Use, and Statistical Analysis Methods. 2a Ed. 1997, Milwaukee, Quality Press.

IBGE, 2013. Estatísticas: Indústria da Construção. Disponível em:

<http://downloads.ibge.gov.br/downloads_estatisticas.htm>. Acesso em: 10 jan. 2016.

IBGE, 2014. Pesquisa Anual da Indústria da Construção. Vol. 22, p. 1- 98, Rio de Janeiro: 2012.

IPEA - INSTITUTO DE PESQUISA ECONÔMICA APLICADA. Evolução das despesas com habitação e transporte público nas pesquisas de orçamentos familiares (POF's): análise preliminar - 2002 a 2009. Brasília: Ipea, dez. 2010. (Comunicados do Ipea, n. 69).

Lordsleem Jr., A.C., Andrade, F.K.G. and Pinho, S.A.C. (2011). Benchmarking em construtoras: Caracterização das melhores práticas de 04 indicadores de execução de obras. In: VIII Encontro Tecnológico da Engenharia Civil e Arquitetura-ENTECA, Maringá, 1-12.

Lordsleem Jr. A. C. and Lima, B.E.G. (2014). Indicators Benchmarking of CementBased Construction Technologies: Brazilian Case Study. Open Journal of Civil Engineering, 4, 301-310. http://dx.doi.org/10.4236/ojce.2014.44025.

MONTEIRO FILHA, D. C.; COSTA, A. C. R.; ROCHA, E. R. P. Perspectivas e desafios para inovar na construção civil. BNDES Setorial, Rio de Janeiro, n. 31, p. 353-410, mar. 2010. Disponível em: < https://web.bndes.gov.br/bib/jspui/handle/1408/4522>. Acesso em: 12 Fev. 2016.

NUNNALY, J. C., Psychometric Theory, McGraw-Hill Book Company, New York, 1967.

PAULA, J. M. P. Infraestrutura de pesquisa voltada para a indústria da construção civil. Sistemas setoriais de inovação e infraestrutura de pesquisa no Brasil. Organizadores: Fernanda De Negrini, Flávia de Holanda Schmidt Squeff. Brasília: IPEA: FINEP: CNPQ, 2016. 
ROLIM, C. A., Construção de Instrumento de Auto-Diagnóstico Organizacional: Aplicações ao Serviço Público. Dissertação de M. Sc, Instituto Militar De Engenharia (IME), 1999, Rio de Janeiro, RJ, Brasil.

SENADO FEDERAL. Inovação - País constrói pontes entre ciência e indústria. Em discussão Revista de audiências públicas do Senado Federal. Brasil, n. 12, p. 3233, set. 2012. Disponível em: <http://www.senado.gov.br/ NOTICIAS/JORNAL/ EMDISCUSSAO/ inova cao.aspx>. Acesso em: 01 mar.2016.

SOUSA, N. M. Gestão de Projetos na Construção: modelo de avaliação do desempenho em projetos. Lisboa. 2008. Dissertação (Mestrado em Engenharia Civil) - Instituto Superior Técnico, Lisboa, 2008.

VERGARA, S. C. Projetos e relatórios de pesquisa em administração. São Paulo: Atlas, 2000.

Recebido: 04 jan. 2017

Aprovado: 22 fev. 2017

DOI: 10.3895/gi.v13n1.5272

Como citar:

GOMES, S. V. et al. A busca por financiamento da inovação na indústria da construção civil - Rio de Janeiro. R. Gest. Industr., Ponta Grossa, v. 13, n. 1, p. 197-227, jan./mar. 2017. Disponível em:

<https://periodicos.utfpr.edu.br/rgi>. Acesso em: XXX.

Correspondência:

Silvia Valeriano Gomes

Rua Passo da Pátria, 156, $3^{\circ}$ andar, Sala: 365, Bloco D, São Domingos, Niterói-RJ, Brasil.

Direito autoral: Este artigo está licenciado sob os termos da Licença Creative Commons-Atribuição 4.0

Internacional.

\section{(c) (i)}

